\title{
The more situation control, the more innovation? - Putting the linearity thesis to the test
}

\section{Diether Gebert}

Berlin Technical University,

Department of Human Resource Management, Uilmersdorfer str. 148, 10585 Berlin, Germany.

Fax: 0049-030/312 21787 E-mail: Gebert@perform.ww.tu-Berlin.de

\section{Sabine Boerner}

University of Konstanz, Fach D 88,

Universitätsstr. 10, 78457 Konstanz, Germany

E-mail: Sabine.Boerner@uni-konstanz.de

\section{Ralf Lanwehr}

Berlin Technical University,

Department of Human Resource Management,

Uilmersdorfer str. 148, 10585 Berlin, Germany

\begin{abstract}
For the purpose of promoting innovativeness in organisations, the literature recommends more decentralisation of power and more participative leadership as one dimension of empowerment and, thus, greater situation control for employees. In fact, however, increasing situation control involves specific risks (including coordination problems). Without concurrent integration to cushion these risks through orientation, consensus and trust, increasing situation control leads not to a further increase in innovativeness but to a decline. This first empirical demonstration of the covert curvilinear relationship between situation control and innovativeness in $\mathrm{N}=101$ organisations reveals these risks. At the same time, it calls into question the widespread recommendations in the literature for action on innovation friendly organisations and leadership. Conclusions are drawn from the findings with regard to the theory of innovation promotion and the methodology of innovation research.
\end{abstract}

Keywords: innovativeness; situation control; integration; curvilinearity.

Reference to this paper should be made as follows: Gebert, D., Boerner, S. and Lanwehr, R. (2004) 'The more situation control, the more innovation? - Putting the linearity thesis to the test', Int J. Entrepreneurship and Innovation Management, Vol. 4, No. 1, pp.98-114.

Biographical notes: Diether Gebert, 1940, is Professor at Berlin Technical University, Faculty of Economics and Management, Department of Human Resource Management. He received his $\mathrm{PhD}$ in psychology from LMU Munich. His research interests are in the areas of organization behaviour, leadership, cooperation in teams, and organizational innovation. He has 
published several books and many papers in both German and International Journals on Organization Behaviour and Management.

Sabine Boemer, 1963, is Professor at the University of Konstanz, Faculty of politics and management, Chair of management, especially leadership and strategy. She received her $\mathrm{PhD}$ in business administration from Berlin Technical University. Her research interests include leadership, organizational culture, organizational learning, and the management of cultural industries. She has published some books and papers in both German and International Journals on Organization Behaviour and Management.

Ralf Lanwehr, 1978, received his degree in psychology from the University of Münster, Germany. He is a currently a doctoral candidate at Berlin Technical University, Faculty of Economics and Management, Department of Human Resource Management. He has published papers in several conference proceedings and international management Journals

\section{Introduction}

There is broad agreement in the literature that innovative organisations tend to be decentralised, to grant employees more decision making autonomy and to be characterised by delegatory and participative leadership [1-3]. Thus, innovative organisations exhibit attributes of empowerment [4] that Burns \& Stalker [5] have identified as aspects of the 'organic' organisation.

Common to the organisational and leadership principles that the literature claims to be important for innovativeness - decentralised self-regulation, the decentralisation of decision making powers, the promotion of decision making autonomy, the delegation of complex tasks and corresponding decision making rights, and participative leadership - is that situation control by the led increases. The degree to which employees can shape and influence matters increases. They have the opportunity to try out changes or innovations independently within their areas of responsibility. If they are led participatively, they can also influence their superiors and, thus, initiate projects for change. To this extent, the following theoretical reflections and empirical findings on the construct situation control are significant for both organisational and leadership studies.

Despite repeated reports of inconsistencies in the empirical relationship between variants of increasing situation control and organisational innovativeness [6,7], greater situation control is generally recommended to increase innovativeness, thus taking the linearity premise for granted: the more situation control, the more innovativeness.

We confront this recommendation with the thesis that an increase in situation control systematically causes specific unplanned negative secondary effects [8], which not only impede but frustrate any further growth in innovativeness unless the organisation cushions the unplanned negative secondary effects by an appropriate counter-strategy (integration). According to this thesis, the relationship between situation control and innovativeness is only apparently linear but is, in fact, curvilinear. Curvilinearity, as opposed to linearity, means a specific inverted $U$ relationship between situation control and innovativeness (in mathematical terms, a second-degree polynomial with negatively weighted quadratic term). 
It is obvious that proof of covert curvilinearity would have far-reaching consequences. From a practical point of view, the usual recommendations to increase situation control would be problematic, since they underestimate the risk of advising this procedure without specific proposals on how to absorb these risks systematically. From a methodological point of view, for example, bivariate analyses could misjudge how close the relationship between situation control and innovativeness is because of the failure to take into account the fact that the organisation concurrently uses strategies to absorb these risks. Furthermore, quadratic functions would be needed as the basis for determining inverted $U$ relationships statistically and, from a theoretical point of view, any description of conditions for enhancing innovativeness would be incomplete and misleading if the theory takes no explicit account of the risks of extending situation control.

Against this background, we argue in detail the thesis of a covert curvilinear relationship between increasing situation control and innovativeness. On a theoretical basis, we explain why innovation related initiatives can be expected to multiply with an increase in situation control but that specific unplanned negative secondary effects also arise. It is also explained why the postulated risks of increasing situation control can be cushioned by a specifically defined counter-strategy of integration. We go on to test empirically the assumption of a covert curvilinear relationship between situation control and innovativeness and the associated thesis of the buffer effect of integration. On the basis of our findings, we then deal in greater depth with the practical, theoretical and methodological implications.

\section{Theory}

\subsection{Innovation friendly effects of situation control}

By innovativeness we mean the capacity of an organisation to improve existing products and/or processes [3] and the capacity to utilise the creativity resources of the organisation to the full. In discussing innovativeness, we do not have in mind the technological innovations or product innovations developed by R\&D specialists. We are thinking about innovation in the structuring of operations, process innovation, and also new (including administrative) offerings for external and internal customers, which in all functional areas ultimately make the organisation more cost-effective, better and faster and, thus, more competitive. We regard innovativeness, thus defined at the aggregate level of the organisation, as a function of the innovation related initiatives of employees implemented per unit of time in the organisation. The implementation rate is, amongst other things, a function of the situation control of employees.

Situation control means the degree of perceived susceptibility of a situation to change, i.e., the extent to which members of the organisation believe they can contribute directly by their own action or indirectly by actualising the resources of others to the innovative improvement of the situation. 
Situation control and innovativeness are linked theoretically in a model formulated by Gebert [9] and empirically tested by Boemer [10], which is based on Lazarus' [11,12] stress management theory. We examine the relationship between situation control and innovativeness in the first place at the disaggregated level of the individual. We assume that a double process of appraisal precedes any innovative initiative on the part of employees.

Figure 1. Situation control as catalyst for innovativeness

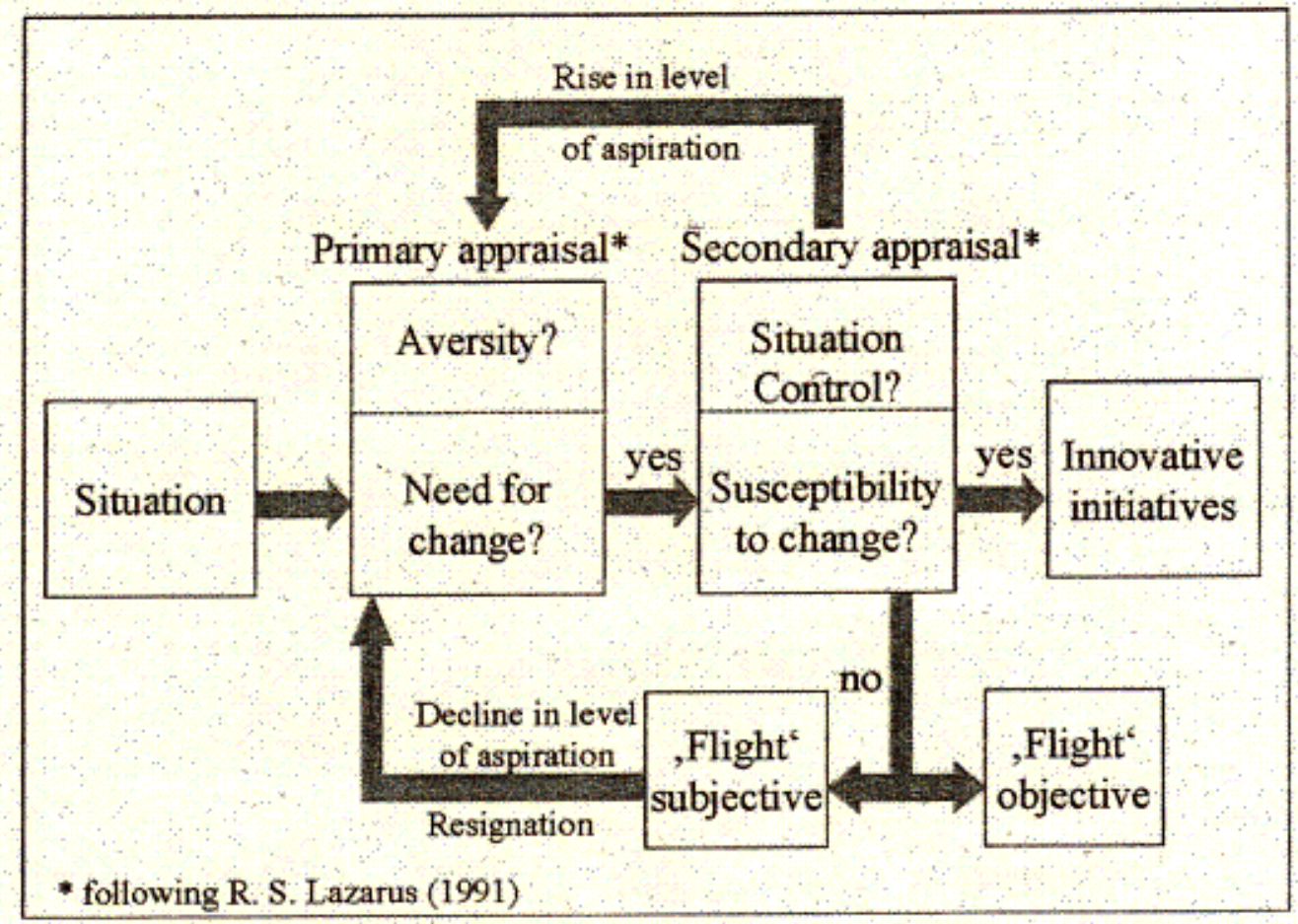

Source: Lazarus [12]

Any action with the aim of innovative improvement presupposes both that a need for change in the situation is recognised and that a susceptibility to change is perceived [9]. The first evaluative process is concerned with the need for change. A situation is categorised as needing change when employees perceive a discrepancy between aspirations and actuality in the corporate situation. The measure of this discrepancy, therefore, determines the degree to which change is needed and, thus, the perceived need for innovative initiative. If no need for change is perceived, employees develop no innovative initiative.

Where a need for change is seen (actuality $<$ aspirations), the controllability of the situation is examined in a second process of appraisal. If sufficient situation control is detected, the person concerned develops innovative initiative in the hope of improving the situation that needs to be changed. For this reason, we assume a positive relationship between the degree of situation control and the number of innovative initiatives. 
If a need for change is established in the course of primary appraisal but secondary appraisal judges the situation not susceptible to change, and if the person concerned cannot objectively withdraw from the situation, resignative adaptation occurs. The demands made of the situation by the employee are lowered and/or the actual position is upgraded by embellishment. The original aspiration/actuality discrepancy is, thus, subjectively reduced, so that, as a result of this reappraisal, the situation is no longer perceived as needing to be changed. In this constellation it is likely that no initiative for innovation will be forthcoming from employees. An additional risk of resignative adaptation processes lies in their generalisation to fields where change is possible and desired [13].

The need for change (the degree of discrepancy between aspirations and actuality) and the susceptibility to change is thus linked multiplicatively; if one of the variables shows a value of 0 , the willingness to take innovative action tends towards 0 . This can be explained from a motivational point of view in terms of expectancy theory [14]. As the need for change in the situation grows, the expected benefits from an initiative for change increase; with increasing susceptibility to change, the assumed probability of the occurrence of this benefit increases. Since expectancy theory generally sees the resulting effort as a function of the product of benefit and probability [14], innovative effort is also a function of the product of willingness to change and the capacity for change.

If the situation is perceived as needing change and as susceptible to change, innovative action can be expected to find sufficient incentive. Leadership behaviour that positively impacts on the perceived susceptibility of the situation to change, therefore, also proves empirically to be at least potentially conducive to innovativeness [10]:

For many innovations, decisions on experiments and test runs in the context of organisational learning about, for example, the generation of new if-then rules [15] cannot be decentralised but have to be made centrally. In this case, it is crucial for employees to be able to communicate perceived needs for change up the hierarchy with subjective and objective prospects of success, so that, at least indirectly (by actualising executive resources), they can categorise the situation as susceptible to change. This is one of the theoretical values of participative leadership it raises the subjective probability of desired changes being feasible. The vertical communication thus encouraged, which makes tacit knowledge public and, in the sense of organisational learning, available for further processing by others, is repeatedly stressed as a significant factor for innovativeness $[3,16-18]$.

It can thus be argued that increasing situation control for the members of an organisation promotes its innovativeness because resignative adaptation processes are avoided and innovation friendly initiatives on the part of organisation members are enabled [1], which constitute the raw material for later innovation at the level of the organisation.

\subsection{Negative secondary effects of greater situation control}

In the wake of increased situation control, however, unplanned negative secondary effects are to be expected. These effects ultimately mean that, although there are more innovative initiatives, the implementation rate falls (see Figure 2) if the unplanned negative secondary effects are not appropriately cushioned. 
Figure 2 Negative secondary effects of greater situation control on innovativeness and their compensation by integration

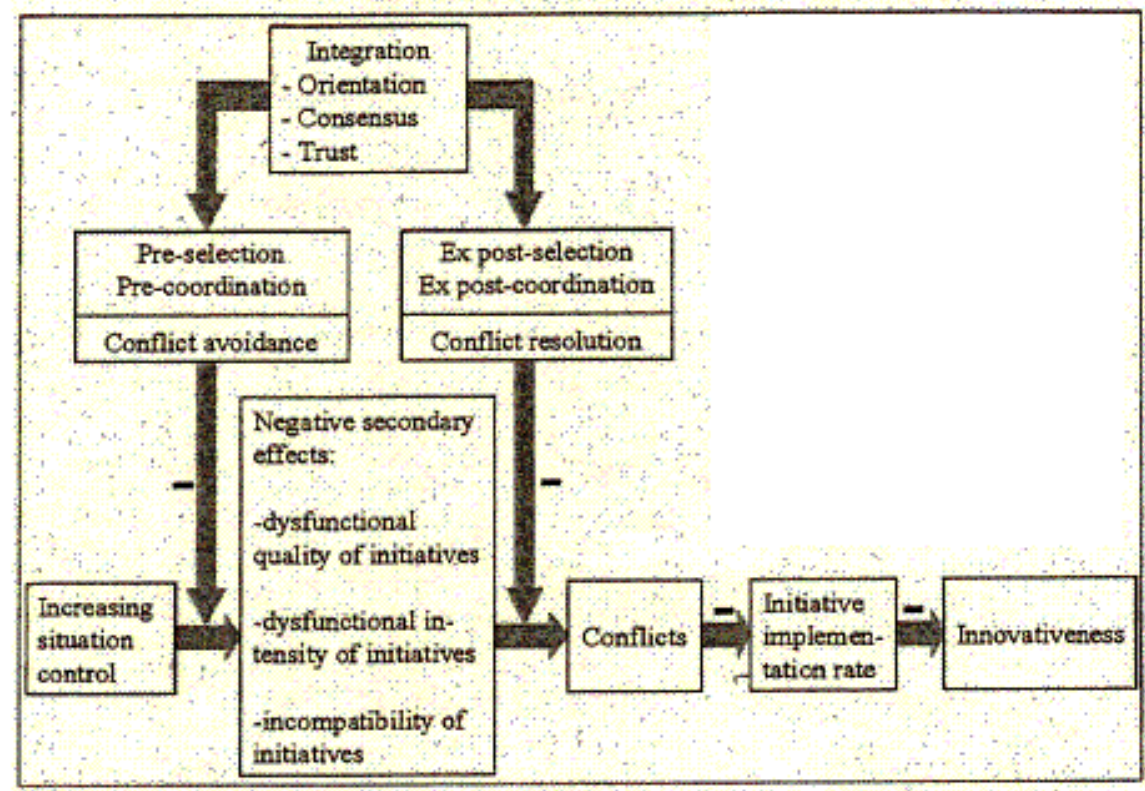

If the situation is increasingly perceived as susceptible to change, employee aspirations generally grow relative to existing corporate practices. Expectations are raised and the value of the current position lowered. As the perceived susceptibility to change increases, so does the potential for criticism (lowering the value of the current position) because characteristics of the existing situation are interpreted less and less as being subject to material constraints [9]. On the other hand, aspirations grow because the situation being perceived as susceptible to change, the search for alternative aspirations (for example, by comparison with other situations in other companies) is activated. This process of raising the aspiration level can - with reference to Figure 1 - be interpreted as positive feedback from the process of secondary appraisal to that of primary appraisal [12]. If a situation is perceived as susceptible to change, there is a greater tendency to perceive it as needing change. Raising the level of aspiration thus mirrors the decline in the level of aspiration described above (see Figure 1).

However, as a result of this rise in the level of aspiration (lowering the value of the current position and raising the level of expectations), which is in principle to be seen as favourable from the point of view of activating initiative, the following three unplanned negative secondary effects occur:

- dysfunctional qualitative orientation of innovative initiatives. Reflecting a higher level of aspiration, the number of innovation related initiatives that are not constructive and, therefore, not worth implementing increases with the rise in the absolute number of initiatives for change originated by employees

- dysfunctional intensity of innovative initiatives. The time and energy spent seeking compromises on innovations is generally experienced as less fascinating than achieving 'absolute, resolute' solutions. An increase in situation control, in the sense. of an expansion of aspirations, therefore, often generates 'everything-or-nothing' and 'now-or-never' attitudes in practice, which tend to give rise to a more radical push for change [9] 
- dysfunctional incompatibility of innovation related initiatives. Augmenting situation control involves the risk of inadequate coordination in substance and timing between various innovative initiatives being tested independently by decision makers in their respective functional areas. This risk is discussed in the literature under the heading autonomy costs of decentralisation [19].

All three effects (dysfunctional qualitative orientation, dysfunctional intensity and dysfunctional incompatibility of innovation related initiatives) imply that; with increasing situation control, not only the number of constructive innovation related initiatives increases but also the number of those that put the goal in jeopardy. If detrimental initiatives outweigh constructive initiatives, the implementation rate declines. The generation of this constellation can be explained as follows.

The three negative secondary effects imply subsequent decisions on the modification or rejection of innovation related initiatives. These decisions require clear selection criteria. Since the existence of such selection criteria cannot be taken for granted, decisions about modification or rejection can lead to conflict, not least because these decisions disappoint the people who have developed the initiatives. Since, although substantive conflicts can be analytically distinguished from relational conflicts [20], they frequently reinforce each other [21], disputes can be expected to escalate. As conflict escalates, even selection criteria that may so far have been respected become less acceptable and binding. The growing void is increasingly filled by the exercise of power and micro-policy $[5,22]$. This increases the danger of constructive innovation related initiatives being rejected and detrimental initiatives being accepted: the implementation rate falls.

Increasing situation control thus proves a Janus-faced strategy, since the unplanned negative 'secondary effects' trigger processes that displace the positive 'primary effects'. If such a development is to be avoided, innovation friendly conflict avoidance and resolution are needed (see Figure 2). This is the purpose of the compensatory counter-strategy of integration.

\subsection{Integration as compensation for negative secondary effects}

We assume that the negative secondary effects of situation control can be compensated for by integration. We understand the construct integration to include cognitive and evaluative-affective aspects. The cognitive aspect of integration ('orientation') is concerned with the clarity of the organisation's strategic course (clear objectives in basic issues and organisational policy). The evaluative-affective aspect of integration is concerned with the degree to which the organisation's strategic course is shared by all (consensus) and is thus approved. Secondly, the evaluative-affective aspect is concerned with the degree to which mutual confidence (trust) arises as an expression of a clear, shared strategic course (in the sense of a positive sum game), and people consequently feel themselves to be emotionally integrated. Thus, these aspects merely reflect the same construct (integration) from different angles. We explain the compensatory effects of integration as thus defined as follows:

In the first place, integration supports the processes of pre-selecting and pre-coordinating innovation related initiatives, which serve conflict avoidance. 
- orientation, defined in terms of the clarity of the strategic course set by the organisation, is one aspect of integration. The clarity of course determines the direction and cognitive scope for potential innovation related initiatives, thus setting cognitive limits to the process of developing initiatives. In the knowledge of the . long-term organisational course, the pre-selection of innovative initiatives is more purposive, more moderate, and better coordinated. Additionally, needed interpersonal pre-coordination is also facilitated by the evaluative-affective aspects of integration (consensus and trust)

- we define consensus as the capacity to reach agreement within the organisation on fundamental issues. Consensus obviates debates on principles when specific innovative initiatives are to be modified in the course of pre-coordination

- we define trust as mutual willingness to accept vulnerability (even without contractual protection) $[23,24]$. Trust reflects the experience of mutual fairness and reliability [25]. In the context of positive-sum games, this experience reduces the likelihood of micro-political intentions being mutually imputed in the course of precoordination, when changes in innovative initiatives are under discussion.

By fostering preselection and precoordination, integration thus contributes to the following effect: the number of dysfunctional innovation related initiatives for change declines, so that the rate of successful innovation implementation rises.

But integration is needed for another reason, too. Even when orientation, consensus and trust are highly developed, the quantity of detrimental innovation related initiatives are not reduced to zero. This is impossible if only because, although the cognitive scope for innovation related initiatives defined by orientation is limited, it nevertheless remains subject to interpretation and, to a certain extent, ambiguous.

For this reason, too, not only preselection and precoordination are needed in practice, but also ex post selection and ex post coordination are needed, as well as appropriate conflict resolution, when specific innovation related initiatives need to be rejected or changed. Keeping in mind the reasons we have given for why the rate of successfully implemented initiatives declines in the face of inevitable subsequent decisions on modifying or rejecting innovative initiatives, it is clear that the counter-strategy of integration favours the implementation rate because it promotes conflict settlement.

As integration intensifies, the unplanned negative effects of increasing situation control are effectively cushioned by conflict avoidance and later conflict resolution. However, this means that without such compensation, an organisation can find itself in difficulties that can substantially jeopardise innovativeness. This is obviously also realised by consultants and companies [26]. This explains why, on the one hand they advocate empowerment and entrepreneurship (corresponding to increasing situation control) whilst on the other stressing visionary leadership and the importance of trust in the organisation (corresponding to increasing integration). If renowned businesses embrace such practices, they are emulated by other companies [27] so that the compensatory strategy of integration is more broadly diffused.

For this reason, we expect the degree of situation control in organisations to be positively linked with the degree of integration. Organisations that take no compensatory measures to counter increasing situation control would, according to this approach, run the risk of losing their innovativeness and, thus, their competitiveness. Finally, we assume that, because of the concurrent integration processes, the empirical observer gains the impression that the innovativeness of an organisation grows as situation control 
increases (in terms of the linearity thesis). If, in contrast, the degree of integration were to be kept constant, it should be apparent that, in keeping with the curvilinear thesis, innovativeness declines from a certain level of situation control.

The hypothesis to be tested is as follows: if integration is held constant, situation control and innovativeness exhibit a (inverted $U$ ) curvilinear relationship; if integration is concurrent, the relationship is linear.

\section{Empirical study}

\subsection{Measurement}

Standardised instruments are available in the literature for measuring the three constructs: situation control, integration and innovativeness [28]. We have, nevertheless, decided to develop our own scales for examining the question of covert curvilinearity. The main reason is that existing scales (e.g., for measuring situation control) have been developed in a different theoretical frame of reference (e.g., stress research; cf. [12]), so that their validity is limited with regard to the constructs defined here.

The operationalisation of the constructs permits the posited theoretical relations to be tested - and this is our central purpose - only if all three constructs are substantively defined in a common theoretical frame of reference. The degree of freedom in construct definition is, therefore, not arbitrary. For this reason, too, the use of scales embedded in other theoretical conceptions is also out of the question.

The construct, situation control, embedded in the theory shown in Figure 1 was operationalised with the following items (the data were collected in standardised form on a five-point scale: strongly agree, agree, uncertain, disagree, strongly disagree).

- in this company employees have the feeling they can discuss even fundamental company practices with management (S1)

- we have learnt that you can elude material constraints (S2)

- employees here think a lot needs to be changed but that change is impossible (recoded) (S3)

- we've come to the conclusion that practically everything can be done otherwise (S4)

- the success of this company is attributed mainly to the ability to get things moving and to bring about change actively (S5)

- in our experience, you can generally achieve more in this organisation than it would seem at first (S6).

The construct integration (consensus, orientation, trust), as defined above, was operationalised with the following items:

1 Orientation (O)

- many feel a lack of reliable orientation on fundamental issues (recoded) (O1)

- the top management in this organisation always succeed in giving employees a clear basic orientation $(\mathrm{O} 2)$

- even if a person is sometimes at a loss on details, the general direction of the task is clear (O3). 


\section{Consensus (C)}

- in your organisation everyone pulls together, there is no quarrelling that could seriously endanger unity (C1)

- conflicts about the matter itself seldom end in protracted debates on principles (C2).

3. Trust (T)

- in your organisation people can show their weaknesses without it being used against them (T1)

- we're very far from being a trusting organisation (recoded) (T2)

- without backing from your superior, no one here takes a risk (recoded) (T3).

In operationalising innovativeness we set the following seven questions concerning comparison with competitors, comparison with own past innovativeness, and comparisor between the innovativeness attained and own innovative potential. As we see it, only the combination of these three aspects permits a valid measurement of innovativeness; taking only one of the three measures into account gives a one-sided and, thus, less valid picture.

- with regard to innovativeness (e.g., creativity, new products, new processes), is your company or the division you are assessing better, just as good, or worse than its competitors? (I1)

- in your opinion, is the available potential for innovativeness/creativity fully exploited in your company (to a low degree, partly, to a high degree)? (I2)

- over the past three years, has your company been better, just as good, or worse than before as regards innovativeness (e.g., creativity, new products, new processes)? (13)

- if we want to be as innovative as our best competitor, we still have a long way to go (recoded) (14)

- the last innovation in our organisation that was really important for the success of the company was years ago (recoded) (I5)

- our company has a reputation among internal/external customers for creative, innovative problem-solving (I6)

- crucial innovation/creativity resources lie fallow in this organisation (recoded) (17).

It was impracticable in this study to record objective indicators of innovation to validate the measurement of innovativeness. An earlier study [29] that examined $\mathrm{N}=25$ SMEs showed a systematic positive relationship between innovativeness rating (I1) (see above) and the development of sales in these companies (measured by objective economic data) $(\mathrm{r}=.51 ; \mathrm{p}<.005)$. Since innovativeness is considered particularly important for the economic development of small and medium sized enterprises, we interpret this finding as indirect evidence of the criterion-related validity of this innovativeness measurement. With regard to the reliability of measurement of the three constructs situation control, integration, and innovativeness, the following results emerged:

On the basis of these three reliable scales, the six items on situation control are summated under the heading 'situation control', eight items on integration under 'integration', and the seven items on innovativeness under 'innovativeness'. 
Table 1 Reliabilities (Cronbach's $\alpha$ ) of the measured constructs

\begin{tabular}{lcc}
\hline Construct & \#Items & Reliability $(\alpha)$ \\
\hline Situation Control & 6 & 0.758 \\
Integration & 8 & 0.808 \\
Innovativeness & 7 & 0.901 \\
\hline
\end{tabular}

\subsection{Sample}

In this study, the number of respondents corresponds to the number of organisations or organisations units under investigation $(\mathrm{N}=101)$. In contrast to studies in which respondents are recruited from only a few organisations, variance in this investigation is organisational rather than personal. Only executives were interviewed (mostly departmental managers). We approached the randomly selected respondents personally; presumably as a result of this personal contact, the response rate was $65 \%$.

A remark on the size of the entities at issue: in the case of smaller and medium sized enterprises, the organisation was generally taken as a whole. For larger companies and multinational groups, respondents were asked to restrict themselves to one subsystem with which they were sufficiently well acquainted and which appeared to be sufficiently homogeneous to justify treatment as a unit. A 'subsystem' in this sense could be, for example, a division or functional area of a company, a decentralised manufacturing facility, a strategic business unit, a research laboratory, a regional branch operation, an independent subsidiary, a branch office, or a major sales department within a company. The 101 organisations or organisational subsystems were recruited in the service sector (insurance, banking, consultancy, media) and manufacturing (motor vehicles, chemicals, electric and electronic equipment, mechanical engineering).

\subsection{Results}

Table 2 shows correlations between the three central variables situation control, integration, and innovativeness.

Table 2 Correlation coefficients between situation control, integration, and innovativeness

\begin{tabular}{lcc}
\hline & Innovativeness & Integration \\
\hline Situation Control & $639^{* * *}$ & $.591^{* * *}$ \\
& $(\mathrm{~N}=95)$ & $(\mathrm{N}=97)$ \\
Integration & $.634^{* * *}$ & \\
& $(\mathrm{~N}=93)$ & \\
\hline
\end{tabular}

*** significant for $\mathrm{p}<0.001$.

All three variables show significant positive intercorrelation. The magnitude of the correlations is striking. This can be explained by, among other things, the fact that all three central constructs (situation control, integration, and innovativeness) were assessed by the same person, resulting in single subject response consistency bias. Although different authors weight this problem differently $[30,31]$, the validity can be diminished and this must be seen critically. 
Furthermore, single subject response consistency bias would reinforce the linear relationship between situation control and innovativeness, thus lending support to the linearity thesis. Under these conditions there would be a bias in favour of the linearity thesis, so that we are testing our thesis of curvilinearity under systematically exacerbated conditions. In these circumstances, confirmation of the curvilinearity thesis would be a robust finding.

In substance, our central thesis is that the relationship between situation control and innovativeness takes the covert curvilinear form of an inverted $\mathrm{U}$, while appearing to be linear because concurrent integration cushions the unplanned negative secondary effects of a higher measure of situation control.

In keeping with this hypothesis, the organisations under study do indeed tend clearly to increase integration with increasing situation control. If we want to show that the covert non-linearity between situation control and innovativeness is disguised by the parallel operation of the buffer 'integration' and that the relationship between situation control and innovativeness thus only appears to be linear, the positive correlation between situation control and innovativeness (see Table 2) is not sufficient evidence, because at the methodological level this statistic presupposes linearity. We must, therefore, also consider whether a quadratic function, in the sense of an inverted $\mathrm{U}$ function, does not underlie the relationship between situation control and innovativeness. Only if this quadratic term is also not significant can the data on the relationship between situation control and innovativeness be interpreted de facto as indicating linearity. Were the quadratic term significant, this would mean that integration does not perform a buffer function and that curvilinearity is not disguised. In Table 2, curvilinearity would then only have been rendered unrecognisable by the wrong choice of statistic. Table 3 shows the results of this check with the aid of regression analysis.

Table 3 Regression coefficients $(\beta)$ of situation control on innovativeness

\begin{tabular}{lcc}
\hline $\mathrm{R}$ & $\beta_{\text {Linesr }}$ & $\beta_{\text {Quadratic }}$ \\
\hline $646^{* * *}$ & $.614^{* * *}$ & -.100 \\
\hline
\end{tabular}

****significant for $\mathrm{p}<0,001$

The quadratic term is not significant Consequently, the assumption of a linear relationship between situation control and innovativeness fits the given data situation. The result reflects the circumstance that, with increasing situation control, the buffer of integration is not only employed but is also effective, and thus disguises the covert curvilinearity of the relationship between situation control and innovativeness that we posit. To be more precise, the data thus far reported do not contradict this interpretation.

If one wished to reveal the risks of a marked and one-sided increase in situation control (i.e., the potential inverted $U$ form of the relationship between situation control and innovativeness), integration processes covariant with situation control that cushion the negative secondary effects of situation control must be controlled for and their effect eliminated in computing the correlation between situation control and innovativeness.

On the basis of these underlying assumptions (see Figure 2) a semi partial correlation seems suitable, where integration is controlled for in situation control but not in innovativeness. The reason is as follows: according to theory, negative secondary effects are to be absorbed, which we regard as a function of an increase in situation control. In order to show what connection there is between situation control and innovativeness if 
the negative secondary effects are not absorbed through integration, integration must be controlled for in the variable that mediates the negative secondary effects, i.e., in situation control. Since we assume no direct relationship between integration and innovativeness in our model (see Figure 2), additionally controlling for integration in innovativeness would not correspond exactly with our theoretical assumptions.

As we have shown, we expect situation control to relate linearly to innovativeness with accompanying integration, and curvilinearly without parallel integration. Our specific assumption structure thus justifies only controlling for integration in situation control.

This is done by only taking account of the residuals of the regression of integration on situation control. If the level of integration were kept constant in this way, the risks of increasing situation control (and thus the posited covert curvilinearity) would have to be apparent. The results of this test are shown in Table 4 .

Table 4 Regression coefficients ( $\beta$ ) of situation control on innovativeness âfter controlling for the impact of integration

\begin{tabular}{lll}
\hline $\mathrm{R}$ & $\beta_{\text {Linear }}$ & $\beta_{\text {Quadratic }}$ \\
\hline $.409^{* * *}$ & $.358^{* * * *}$ & $-.244^{*}$ \\
\hline
\end{tabular}

* significant for $\mathrm{p}<0,05 ; * * *$ : significant for $\mathrm{p}<0,001$

If, after controlling for the effect of integration, we take the inverted $U$ function - a quadratic function - as the basis, the quadratic term is significant, as Table 4 shows. This means nothing other than that, after controlling for integration, the function between situation control and innovativeness does not rise in constant linearity but reaches a maximum beyond which it falls again. Precisely this finding confirms our central hypothesis (see Figure 3).

Figure 3 Relationship between situation control and innovativeness (controlling for the effects of integration)

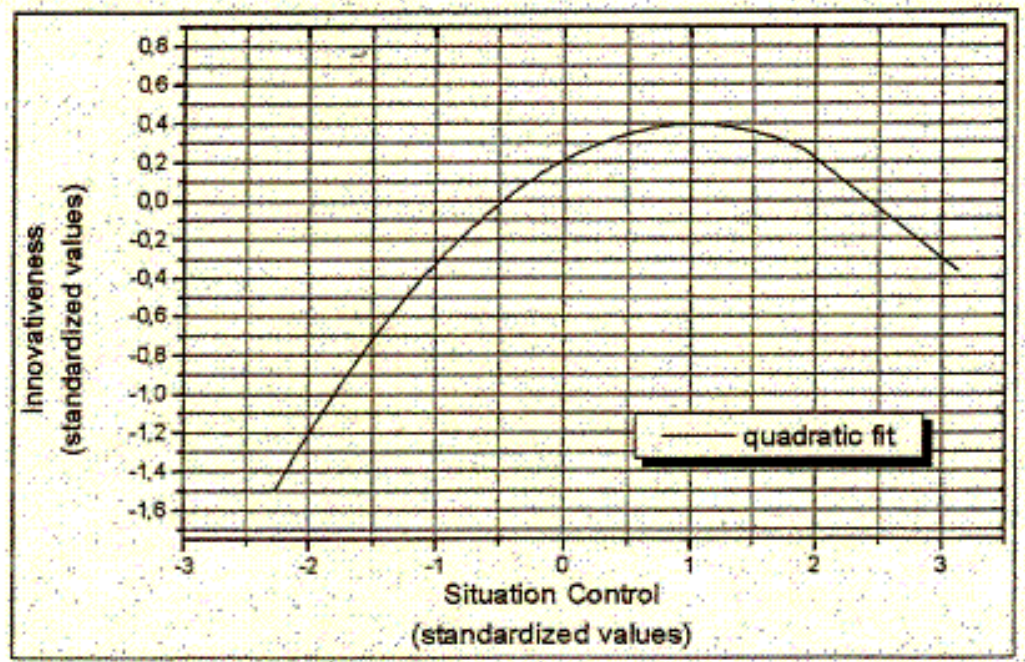

As Table 4 shows and Figure 3 illustrates, the linear term is also significant. But this is irrelevant for our hypothesis testing, since confirmation of our central hypothesis of a covert curvilinear relationship demands only that the quadratic term be significant. The 
significance of the linear term can be explained as follows: since organisations that takt no compensatory measures to counter increasing situation control forfeit thei competitiveness in the medium term (see above), no curvilinearity taking the form of ar inverted $\mathrm{U}$ is in empirical evidence. If this was the case, the linear term would no longe prove significant. Since the fall of the function beyond the maximum has the empirica limit mentioned, the concretely evident function is both linear and quadratic.

\section{Conclusions}

To begin with, a number of relativising remarks on method are called for. In order tc avoid the single subject response consistency bias, future studies would have to collec the data on situation control and integration and that on innovativeness from independen sources.

Furthermore, despite good scale reliability (Cronbach's alpha), certain iten formulations appear to require revision to eliminate linguistic ambiguity. Thirdly, i would have been useful not only to specify unplanned negative secondary effect: substantively at the theoretical level but also to measure them.

The thesis - supported by eliminating the impact of integration and in cross-sectiona examination - that increasing innovativeness tends to decline from a certain level onwari in the absence of compensatory integration, needs to be confirmed by longitudina studies. The provocation of unplanned negative secondary effects and how thi organisation copes (or fails to cope) with them needs to be documented. It is only on thi basis that the posited concatenation of effects in Figure 2 can be specified and tested.

Since the central thesis of covert curvilinearity is also confirmed by preparator. studies with different samples with slightly modified measurements, we assume, despit these reservations, that the findings of this study can be replicated. Against thi background, we proceed to discuss the implications of our investigation.

\section{I Remarks on practical implications}

The successful demonstration of covert curvilinearity has a number of implications Since the frequently recommended procedures of decentralised self-regulation decentralisation of decision making powers, the promotion of decision making autonom: and empowerment as well as participative leadership imply an increase in situation control, they are associated not only with opportunities but also with identifiable risk (hitherto little discussed in the literature).

With regard to innovativeness, there can not only be too little situation control but where not absorbed, too much. Burns \& Stalker [5] and later Alderfer [32] ani Brown [33] have warned against absolutising the strategies of decentraliser self-regulation, the promotion of decision making autonomy, etc., although thei terminology differs. At the practical level, solving this problem by dosing situation control proves very difficult. Since there is no clear yardstick for situation control and thi optimum is unknown ex ante, practitioners can often act only ex post, when innovativi initiatives either peter out or develop into prospectively uncontrollable destabilisation o the organisation. Not infrequently, an everything-or-nothing attitude and now-or-neve thinking arise as well, especially among younger employees, with the result that member of the organisations are not to be satisfied with gradual increases in situation control. 
To this extent a strategy of compensation is preferable to one of dosing. The promotion of orientation, consensus and trust seems to be the counterweight that prevents the actuation of initiatives and change from veering into conflict escalation and paralysis. Under these conditions, the relationship between situation control and innovativeness is in fact linear and does not merely appear to be linear, so that innovativeness does not begin to decline with increasing situation control but continues to rise.

From a practical point of view, transformational leadership, operationalised in accordance with Avolio \& Bass et al. [34], is relevant in this context. The trust bonus of leaders vis-à-vis the led allows a potential for trust to develop; an inspiring common vision enables orientation and builds a potential for consensus. In this way, the risk of increasing situation control through delegation and participation can be cushioned [35].

As we have seen, companies tend to favour this buffer strategy. Nevertheless, the need for it must be stressed: as our empirical analysis has shown, there are companies that do not consistently practice such compensation. Moreover, it is important, for practical reasons, to describe and justify the content of the strategy more precisely to permit more effective action.

\subsection{Theoretical-methodological remarks}

Besides the planned, positive primary effects, the unplanned, negative secondary effects of a specific leadership and organisational model need to be clarified on a theoretical basis, as we have attempted to demonstrate here with reference to Lazarus' stress management theory [12]. Only thus is it possible (purposively) to consider what compensatory strategies to absorb these negative effects are additionally needed in substance if the planned, positive primary effects are to be safeguarded.

To this extent, leadership must be seen as a self-reflexive process, which responds not only to changes in the environment but also to changes caused by leadership itself. Although Katz and Kahn [36] drew attention to this complex in similar fashion at an early stage, due notice has still not been taken of the issue in leadership research.

On the theoretical level, it is likely to be instructive from the self-regulation perspective to examine the dynamic relationship between the sub-strategies of situation control and integration more closely. Increasing situation control can be interpreted as expanding scope for action, and the communication of clear orientation (also) as limiting this scope (see above). While expanding the scope for action involves a risk of destabilisation and paralysis, restricting such scope risks tutelage and rigidity. To this extent, expansion determines its limitation and vice versa $[5,37]$. This is why situation control and integration correlate relatively closely (see Table 2) - and not only because consultants recommend this double strategy. Interventions are thus needed that seem paradoxical, as reflected in formulations in the literature like 'flexibility through stability' [38]. At the theoretical level, the absorption problem can thus, presumably, be profitably reconstructed as a problem of balancing out antagonistic, interdependent forces [5,38-42], and thus situated in a general theoretical context.

Among other things, this study suggests that statistical correlation analyses, including meta-analyses based on them, run the risk of systematically obscuring existing covert curvilinearities as such. Our example of the relationship between situation control and innovativeness demonstrates precisely this. To this extent, traditional correlation studies need to be supplemented by, for example, analyses using the methods we propose in order to build in a methodological corrective. 


\section{References}

1 Axtell, C.M., Holman, D.J., Unsworth, K.L., Wall, T.D. and Waterson, P.E. (2000) 'Shopfloor innovation: facilitating the suggestion and implementation of ideas', Journal of Occupational and Organizational Psychology, Vol. 73, pp.265-285.

2 Damanpour, F. (1991) 'Organizational innovation: a meta-analysis of effect of determinants and moderators', Academy of Management Review, Vol. 34, No. 3, pp.555-590.

3 Glynn, M.A. (1996) Innovative genius: a framework for relating individual and organizational intelligences to innovation', The Academy of Management Review, Vol. 21, No. 4, pp.1081-1111.

4 Hardy, C. and Leiba-O'Sullivan, S. (1998) 'The power behind empowerment: implications for research practice', Human Relations, Vol. 51, No. 4, pp.451-483.

5 Burns, T. and Stalker, G.M. (1961) The Management of Innovation, London, Tavistock.

6 Fiol, C.M. (1996) 'Squeezing harder doesn't always work continuing the search for consistency in innovation research', The Academy of Management Review, Vol. 21, No. 4, pp.1012-1021.

7 Wolfe, B. (1994) 'Organizational innovativeness: review, critique and suggested research directions', Journal of Management Studies, Vol. 31, pp.405-431.

8 Gebert, D. and Boerner, S. (1999) 'The open and the closed corporation as conflicting forms of organization', The Journal of Applied Behavioral Science, Vol. 35, No. 3, pp.341-359.

9 Gebert, D. (1987) 'Führung und innovation: leadership and innovation', Zeitschrift fuir betriebswirtschaftliche Forschung, Vol. 39, No. 10, pp.941-951.

10 Boerner, S. (1998) 'Work alienation and continuous improvement', in $\mathrm{H}$. Boer and J. Gieskes (Eds.) Continuous Improvement; From Idea to Reality, Enschede, Twente University Press, pp.63-75.

11 Lazarus, R.S. (1966) Psychological Stress and the Coping Process, New York, McGraw-Hill.

12 Lazarus, R.S. (1991) Emotion and Adaptation, New York, Oxford University Press.

13 Brunstein, J.C. (1996) Entwicklung und stand der hilflosigkeitsforschung development and status of helplessness research', in J. Kuhl and H. Heckhausen (Eds.) Enzyklopädie der Psychologie, Band 4: Motivation, Volition und Handlung, Göttingen, Hogrefe, pp.847-873.

14 Vroom, V.H. (1964) Work and Motivation, New York, Wiley.

15 Cheng, Y.T. and Van de Ven, A.H. (1996) 'Leaming the innovation joumey: order out of chaos?', Organization Science, Vol. 7, No. 6, pp.593-614.

16 Cohen, W.M. and Levinthal, D.A. (1990) 'Absorptive capacity: a new perspective on learning and innovation', Administrative Science Quarterly, Vol. 35, pp.128-152.

17 Grant, R.M. (1996) Prospering in dynamically-competitive environments: organizational capability as knowledge integration', Organization Science, Vol. 7, No. 4, pp.375-387.

18 Lam, A. (2000) 'Tacit knowledge, organizational learning and societal institutions: an integrated framework', Organization Studies, Vol. 21, No. 3, pp.487-514.

19 Frese, E. (1998) Grundlagen der Organisation: Konzept-Prinzipien-Strukturen, Fundamentals of Organization: Concept-Principle Structures, Wiesbaden: Gabler.

20 Jehn, K.A. (1995) 'A multimethod examination of the benefits and detriments of intragroup conflict', Administrative Science Quarterly, Vol. 40, No. 2, pp.256-282.

21 Pelled, L. (1996) 'Demographic diversity, conflict, and work group outcomes: an intervening process theory', Organization Science, Vol. 7, No. 6, pp.615-631.

22 Pfeffer, R.J. (1992) Managing with Power, Boston, Harvard Business-School Press.

23 Deutsch, M. (1973) The Resolution of Conflict, London, Yale University Press. 
24 Rippberger, T. (1998) Ökonomik des Vertrauens, Economics of Trust, Tübingen, Moor-Siebek.

25 Rousseau, D., Sitkin, S.B., Burt, R.S. and Camerer, C. (1998) 'Not so different after all: a cross-discipline view of trust', The Academy of Management Review, Vol. 23, No. 3, pp.393-404.

26 Hardy, C. and Leiba-O'Sullivan, S. (1998) 'The power behind empowerment: implications for research practice', Human Relations, Vol. 51, No. 4, pp.451-483.

27 Greenwood, R. and Hinings, C.R. (1996) 'Understanding radical organizational change: bringing together the old and new institutionalism', The Academy of Management Review, Vol. 21, No. 4, pp.1022-1054.

28 Cooper, R.G. and Kleinschmidt, E.J. (1995) 'Benchmarking the firm's critical success factors in new product development', Journal of Product Innovation Management, Vol. 12, pp. $374-391$.

29 Gebert, D. and Steinkamp, T. (1990) Innovativitat und Produktivität durch betriebliche Weiterbildung, Innovativeness and Productivity Through In-House Training, Stuttgart, Poeschel.

30 Fuller, J.B., Coleman, E.P., Patterson, K.H. and Stringer, D. (1996) 'A quantitative review of research on charismatic leadership', Psychological Reports, Vol. 78, pp.271-287.

31 Keller, R.T. (1992) 'Transformational leadership and the performance of research and development project groups', Journal of Management, Vol. 18, No. 3, pp.489-501.

32 Alderfer, C.P. (1980) 'Consulting to unbounded systems', in C.P. Alderfer and C.L. Cooper (Eds.) Advances in Experimental Social Processes, Chichester: John Wiley \& Sons, Vol. 2, pp.267-295.

33 Brown, L.D. (1980) 'Planned change in underorganized systems', in T.G Cummings and J. Gieskes (Eds.) Systems Theory for Organizational Development, Chichester, Wiley, pp:181-203.

34 Avolio, B.J., Bass, B.M. and Jung, D.I. (1999) 'Re-examining the components of transformational and transactional leadership using the multifactor leadership questionnaire', Journal of Occupational and Organizational Psychology, Vol. 72, pp.441-462.

35 Lowe, K.B., Kroeck, K.G. and Sivasubramaniam, N. (1996) 'Effectiveness correlates of transformational and transactional leadership: a meta-analysis review of the MLQ literature', Leadership Quarterly, Vol. 7, pp.385-425.

36 Katz, D. and Kahn, R.L. (1978) The Social Psychology of Organizations, New York, McGraw Hill.

37 Gebert, D. and Boerner, S. (1995) Manager im Dilemma - Abschied von der offenen Gesellschaft?, Manager in a Dilemma - Farewell to the Open Society?, Frankfurt/Main, Campus.

38 Volberda, H.W. (1996) 'Toward the flexible form: how to remain vital in hypercompetitive environments', Organization Science, Vol. 7, No. 4, pp.359-374.

39 Armbrüster, T. and Gebert, D. (2001) 'Uncharted territories of organizational research: the case of Karl Popper's open society and its enemies', Organization Studies, Vol. 23, No. 2, pp.169-188.

10 Bouchikhi, H. (1998) 'Living with and building on complexity: a constructivist perspective on organizations', Organization, Vol. 5, pp.217-231.

11 Brown, S.L. and Eisenhardt, K.M. (1997) 'The art of continuous change: linking complexity theory and time-paced evolution in relentlessly shifting organizations', Administrative Science Quarterly, Vol. 42, pp.1-34.

42 Dougherty, D. (1996) 'Organizing for innovation', in S.R. Clegg, C. Hardy and W.R. Nord (Eds.) Handbook of Organization Studies, London, Sage Publications, pp.425-439. 